Editorial

\title{
Building Mathematical Models for Multicriteria and Multiobjective Applications 2020
}

\author{
Adiel Teixeira de Almeida $\left(\mathbb{D},{ }^{1}\right.$ Love Ekenberg $\left(\mathbb{D},{ }^{2,3}\right.$ Juan Carlos Leyva-Lopez ${ }^{(D},{ }^{4}$ \\ Danielle Costa Morais $\mathbb{D}{ }^{1}{ }^{1}$ and Tomasz Wachowicz $\mathbb{D}^{5}$ \\ ${ }^{1}$ Department of Management Engineering, Universidade Federal de Pernambuco, Recife, Brazil \\ ${ }^{2}$ International Institute for Applied Systems Analysis (IIASA), Schlossplatz 1-A-2361, Luxenburg, Austria \\ ${ }^{3}$ Department of Computer and Systems Sciences, Stockholm University, Stockholm, Sweden \\ ${ }^{4}$ Department of Economic and Management Sciences, Universidad Autónoma de Occidente, Culiacán, Mexico \\ ${ }^{5}$ University of Economics in Katowice, Katowice, Poland \\ Correspondence should be addressed to Adiel Teixeira de Almeida; almeida@cdsid.org.br
}

Received 22 December 2021; Accepted 22 December 2021; Published 27 December 2021

Copyright (C) 2021 Adiel Teixeira de Almeida et al. This is an open access article distributed under the Creative Commons Attribution License, which permits unrestricted use, distribution, and reproduction in any medium, provided the original work is properly cited.

This is the Fourth Special Issue (SI) dealing with "Building Mathematical Models for Multicriteria and Multiobjective Applications." The first one was published in 2016, and based on its success, another one was published in 2018 and 2019 each and now this one in 2020. The ambition is to henceforth publish an annual Special Issue. This series has been attracting the Multicriteria Decision-Making/Aid (MCDM/ A) and multiobjective community, researchers, and practitioners.

The focus of this Special Issue is to demonstrate how MCDM/A and multiobjective methods can be highly useful for decision-makers (DMs) in solving decision problems involving multiple criteria.

This Special Issue offers seven original research papers covering a variety of applications for real-world problems while combining theoretical methodology and mathematical analysis. The authors of these papers are from Brazil, China, and Thailand. Two papers bring new approaches to deal with group decision-making and negotiation. Two papers discuss applications of the FITradeoff method, and three papers are focused on multiobjective applications.

The paper, which deals with a novel group decisionmaking approach, applies the hesitant fuzzy linguistic term sets (HFLTSs) to elicit the decision-makers' linguistic preferences as they are efficient and flexible in representing uncertainty. The approach considers the advantages of the rough set theory and OWA operators and presents an extended VIKOR method. Another paper brings a novel procedure to pursue aspired procurement negotiation (PN) outcomes using the combined multiple attribute decisionmaking (MADM) model. This model allows identifying, measuring, and depicting suboptimal situations in the context of an influential network relation map (INRM).

The papers which bring applications of the FITradeoff method are focused on ranking problems. One paper discusses a supplier selection for a wholesaler and retailer company of the construction sector to assist the DM in selecting new suppliers to keep the products and suppliers in line with the company's strategic plans and objectives. The other paper presents the multicriteria decision model that prioritizes sections of Brazilian roads by criticality and the risk of their use for drivers. The goal is to ensure an efficient movement of traffic under stable conditions and minimal traffic congestion, i.e., keep the federal highways safe and prevent accidents.

This Special Issue brings three different approaches concerning multiobjective applications. One paper presents a goal programming approach to nurse scheduling that simultaneously considers workload fairness and individual preferences on working shift and day off assignments. Another paper presents a combination of the Kriging model, optimal Latin hypercube sampling, and particle swarm 
optimization, an algorithm, EIR2-MOEA, for solving expensive multiobjective optimization problems. It is applied to three sets of standard test functions of varying difficulty and compared with two other competitive infill point criteria. Finally, the last paper presents a design-task-oriented model assignment framework that involves model value selection, multiobjective model establishment, and multiobjective optimization algorithm. It provides a solution for the problem of model assignment in the model repository to the design tasks in Model-Based System Engineering (MBSE).

We hope that the papers presented in this Special Issue will be useful and stimulating for further developments and applications of multicriteria and multiobjective models and that we again have been able to highlight the extensive range of contexts over which these methods can be used.

\section{Conflicts of Interest}

The Guest Editors declare that they have no conflicts of interest.

\section{Acknowledgments}

The Guest Editors would like to express their deepest gratitude to the authors for their contributions to this Special Issue and the cooperation and assistance of many reviewers, whose feedback was very useful in improving the quality of papers submitted.

Adiel Teixeira de Almeida Love Ekenberg Juan Carlos Leyva-Lopez Danielle Costa Morais Tomasz Wachowicz 